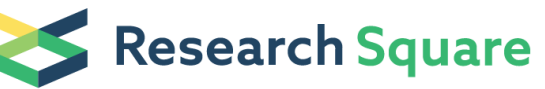 \\ Preprints are preliminary reports that have not undergone peer review. \\ They should not be considered conclusive, used to inform clinical practice, or referenced by the media as validated information.
}

\section{Mycelium chemistry differs markedly between ectomycorrhizal and arbuscular mycorrhizal fungi}

\section{Weilin Huang ( $\nabla$ w.huang@cml.leidenuniv.nl )}

Institute of Environmental Science (CML), Leiden

\section{Peter Bodegom}

Leiden University https://orcid.org/0000-0003-0771-4500

\section{Stéphane Declerck}

Earth and Life Institute, Université catholique de Louvain

\section{Jussi Heinonsalo}

Department of Microbiology and Institute for Atmospheric and Earth System Research (INAR), University of Helsinki

\section{Marco Cosme}

Earth and Life Institute, Université catholique de Louvain

\section{Toni Viskari}

Finnish Meteorological Institute

Jari Liski

Finnish Meteorological Institute

\section{Nadejda Soudzilovskaia}

Ecotron research facility, Hasselt University

\section{Article}

Keywords: soil carbon inputs, mycorrhizal fungi, mycelium chemistry

Posted Date: August 24th, 2021

DOI: https://doi.org/10.21203/rs.3.rs-753513/v1

License: (c) (i) This work is licensed under a Creative Commons Attribution 4.0 International License. Read Full License

Version of Record: A version of this preprint was published at Communications Biology on April 28th, 2022. See the published version at https://doi.org/10.1038/s42003-022-03341-9. 


\title{
Mycelium chemistry differs markedly between ectomycorrhizal and arbuscular mycorrhizal fungi
}

\author{
Weilin Huang ${ }^{1}$, Peter van Bodegom ${ }^{1}$, Stéphane Declerck ${ }^{2}$, Jussi Heinonsalo ${ }^{3,4}$, Marco \\ Cosme $^{2}$, Toni Viskari ${ }^{3}$, Jari Liski ${ }^{3}$, and Nadejda Soudzilovskaia ${ }^{1,5}$ \\ ${ }^{1}$ Environmental Biology, Institute of Environmental Sciences, Leiden University, Einsteinweg 2, 2333CC \\ Leiden, the Netherlands; \\ 2 Mycology, Applied Microbiology, Earth and Life Institute, Université catholique de Louvain, 1348 \\ Louvain-la-Neuve, Belgium \\ ${ }^{3}$ Finnish Meteorological Institute, 00101 Helsinki, Finland; \\ ${ }^{4}$ Department of Microbiology, Institute for Atmospheric and Earth System Research (INAR)/Forest \\ Sciences, University of Helsinki, 00014 Helsinki, Finland; \\ ${ }^{5}$ Ecotron research facility, Hasselt University, Martelarenlaan 42, 3500 Hasselt, Belgium
}

\section{Abstract}

The chemical quality of soil carbon (C) inputs is a major factor controlling litter decomposition and soil $\mathrm{C}$ dynamics. Mycorrhizal fungi constitute one of the dominant pools of soil microbial $\mathrm{C}$, while their litter quality is understood poorly, leading to the major uncertainties in estimating soil $\mathrm{C}$ dynamics. We examined chemical recalcitrance of arbuscular mycorrhizal (AM) and ectomycorrhizal (EM) fungal species using fungal samples obtained from in vitro cultivation. We show that the chemical composition of AM and EM fungal mycelium differs significantly: EM fungi have higher concentrations of labile (water-soluble, ethanol-soluble) and recalcitrant (non-extractable) chemical components, while AM fungi have higher concentrations of acid-hydrolysable components. Our results imply that differences in chemical decomposability traits among mycorrhizal fungal guilds represent a critically important driver of the soil $\mathrm{C}$ cycle, which could be as vital as is recognized for differences among aboveground plant litter.

\section{Introduction}

The soil carbon (C) cycle is among the least understood terrestrial biogeochemical cycles, while it is critically important for ecosystem functioning and mitigation of climate change ${ }^{1,2}$. A major knowledge gap in this field is the lack of data on belowground influxes of $\mathrm{C}$, and their fate in terms of contribution to stable $\mathrm{C}$ pools ${ }^{3,4}$. A particularly poorly understood aspect is the magnitude of $\mathrm{C}$ input into the soil pool of potentially decomposable $\mathrm{C}$ components provided by belowground organisms, and decomposability patterns of these organisms ${ }^{5}$. The chemical quality of the $\mathrm{C}$ components comprising input of $\mathrm{C}$ into the soil is among the key factors that influence the soil $\mathrm{C}$ turnover process ${ }^{6-8}$, and arguably mediate the ultimate fate of soil C, i.e. to be sequestered or respired ${ }^{9}$. Due to the large uncertainty about the contribution of belowground organisms and their chemical 
quality, until now, the largest known source of variability in the quality of $\mathrm{C}$ inputs into the soil has been associated with differences among plant species in terms of aboveground litter quality ${ }^{10-12}$. However, that might be an underestimate of the true variability in the quality of $\mathrm{C}$ inputs.

Our knowledge about the factors that control the decomposability of C compounds entering into the soil pool through residues of microorganisms, especially so from widespread soilborne fungi, is extremely limited. In soil ecosystems, mycorrhizal fungi living in symbiosis with plant roots are among the key soil microorganisms controlling the exchange of $\mathrm{C}$ and nutrients between soil and plants ${ }^{13,14}$. The living and dead biomass of these microorganisms constitute one of the most dominant pools of soil microbial $\mathrm{C}^{15,16}$. Depending on the soil ecosystem environment and mycorrhizal type, mycorrhizal hyphal biomass can constitute up to half of the standing mycelial biomass ${ }^{17}$ and one-third of total microbial biomass ${ }^{15}$. Mycorrhizal fungi are important C sinks of net primary production (NPP) ${ }^{18,19}$, and depending on the mycorrhizal guild, the annual mycelial accumulation can reach around 175-200 $\mathrm{g} \mathrm{C} \mathrm{m}^{-2} 20,21$. This is particularly evident in some forest ecosystems, where the allocation of photosynthesized $\mathrm{C}$ into fungi can represent up to $30 \%$ of the $\mathrm{NPP}^{20,22}$. Yet, the magnitude of the potential contribution of mycorrhizal fungal pools to long-term soil $\mathrm{C}$ storage is unknown. Hence, a quantitative assessment of the chemical composition of microorganisms relevant for assessing the decomposability of microbial necromass is critically needed to narrow down the uncertainties in estimating belowground contributions to soil C pools ${ }^{23,24}$.

44

Among the four principal types of mycorrhiza, the two globally dominant ones are arbuscular mycorrhiza (AM) and ectomycorrhiza (EM) ${ }^{25}$. These soil fungi associate with the roots of most terrestrial plants ${ }^{25}$, and are predominant across the majority of the terrestrial vegetated areas $^{26}$. Ecophysiological traits of these two main guilds of mycorrhizal fungi differ in many aspects (e.g. in the ability of enzymatic degradation of organic matter $)^{27,28}$. Also, the microscopic structure of AM and EM fungal hyphae differs ${ }^{5}$. EM fungal hyphae have thicker walls, pigmentation, and septa between cells, and are generally believed to have a longer life span than AM fungal hyphae ${ }^{16,29}$. These differences in morphology could potentially determine the chemistry quality of EM and AM fungi, and have raised the hypothesis that dead EM hyphae are likely more recalcitrant to decomposition than AM hyphae. However, our knowledge about the chemical differences among mycorrhizal fungal guilds, particularly on the chemical components that contribute differently to necromass decomposition, is remarkably limited.

Thus far, studies of the impacts of decomposition of fungal mycelium on soil organic matter (SOM) have focused primarily on EM and ericoid mycorrhizal fungi ${ }^{30}$, and have examined mostly the abundance of individual chemical components in the fungal mycelium, such as concentrations of nitrogen, chitin and melanin. The latter is known to be negatively correlated to necromass decomposition of mycorrhizal fungal biomass ${ }^{9,31}$. While the outcomes of these analyses shed new light on ecophysiological traits of mycorrhizal fungi at the individual level, they (1) do not provide an integrative assessment 
of the potential fate of fungal biomass in the process of organic matter decomposition, and (2) neglect the most ancient and widespread mycorrhizal fungal guild, currently associated with the largest part of Earth's terrestrial vegetation - the AM fungi ${ }^{25,26}$.

The objective of this study was to fill a main knowledge gap in the soil $\mathrm{C}$ cycle by examining inherent differences between EM and AM fungi in terms of their ultimate decomposability potential. Similar to plant residues that have a variety of components that differ in recalcitrance ${ }^{32,33}$, soil fungi also consist of components of distinct decomposability ${ }^{24}$. Fungi contain relatively recalcitrant components, such as melanin, that require costly oxidative enzymes for further decomposition ${ }^{34}$, as well as relatively labile components (e.g. chitin) that are utilized as a source of $\mathrm{C}$ and $\mathrm{N}$ for the soil microbial community ${ }^{35}$. Upon release, these components enrol in principally different types of physical and chemical interactions with mineral surfaces and soil aggregates ${ }^{3,36}$. Yet the integrative understanding of principal differences among EM and AM fungi in terms of their decomposability is lacking.

An important reason underpinning this knowledge gap is the need for samples of in vitro pure biomass of mycorrhizal fungi to examine their chemical composition. For the AM fungi, this constitutes a particular challenge due to their obligate symbiotic lifestyle, which requires a suitable host root established on a poor medium to avoid any contamination by unwanted microbes. Using unique methods of cultivation of mycorrhizal fungi ${ }^{37-39}$ well established in the laboratory of mycology of the UCLouvain (Belgium), we cultivated multiple species of AM fungi under in vitro culture conditions and obtained amounts of fungal mycelia sufficient to examine their chemical compositions. To assess the differences in chemical traits between AM and EM fungal mycelium, we also cultivated EM fungi in vitro following standard laboratory techniques ${ }^{40}$. We subsequently assessed the chemical recalcitrance of AM and EM fungal mycelium. With this dataset, we tested two hypotheses crucial to understanding the contribution of major mycorrhizal fungal guilds to the soil $\mathrm{C}$ cycle:

(1) AM and EM fungal guilds differ principally in their chemical composition traits relevant for decomposability.

(2) Differences of decomposability between AM and EM fungal guilds are larger than the differences among litters from distinct plant functional types.

\section{Results and discussion}

\section{Distinct chemical composition of $A M$ and EM fungi}

We used 11 species of EM fungi and 4 species of AM fungi from in vitro cultures (CBS/MUL number see Table.S1): EM fungal species are Xerocomus rubellus, Paxillus involutus, Laccaria bicolor, Inocybe rimosa, Hebeloma hiemale, Lactarius deliciosus, Phaeogyroporus sudanicus, Peziza varia, Cortinarius cristallinus, Peziza quelepidotia, and Scleroderma verrucosum; AM fungal species are Rhizophagus clarus, Rhizophagus irregularis, Glomus aggregatum and Glomus hoi. Samples of dried fungal biomass were examined for water-soluble, acid-hydrolyzable, ethanol-soluble and non-extractable 
components (hereafter $\mathrm{W}, \mathrm{A}, \mathrm{E}, \mathrm{N}$ components, respectively), allowing direct comparison of AM and EM fungi for the entire suite of recalcitrance traits (Fig.1).

\section{Chemical fractions of mycorrhizal biomass}

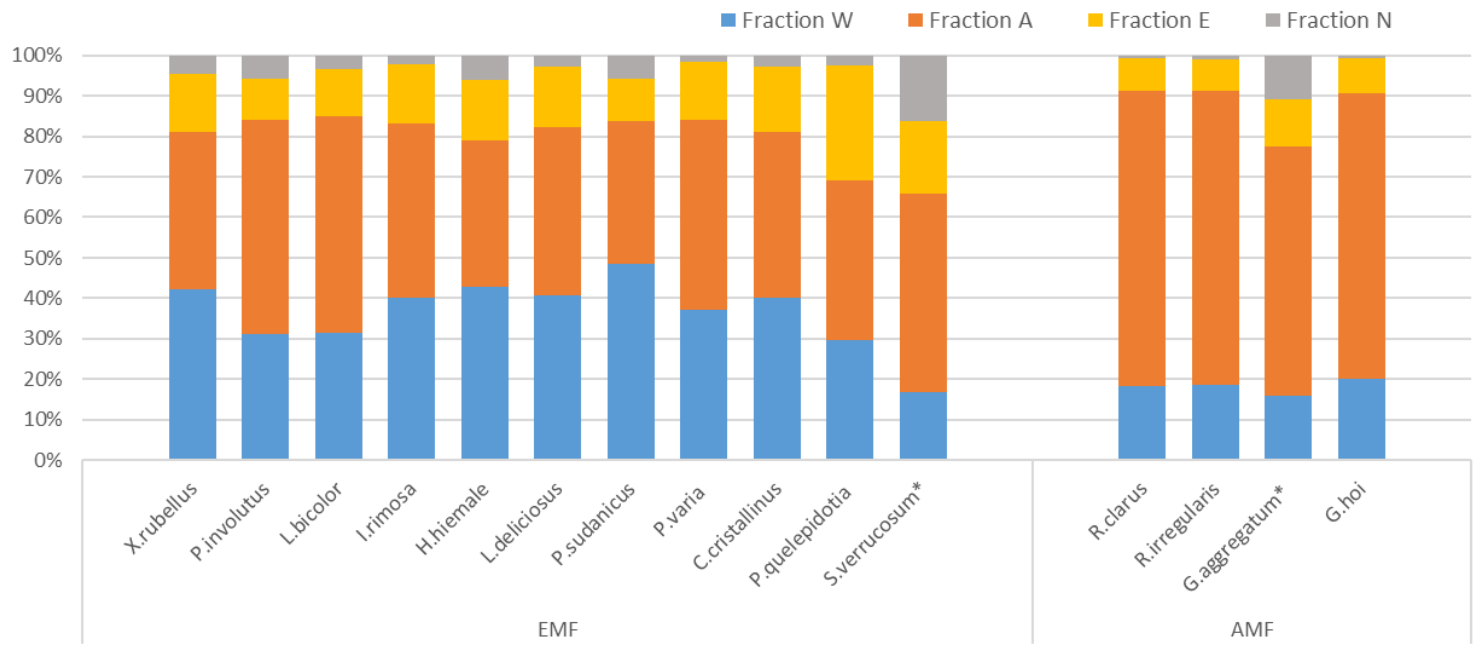

Fig.1 Relative abundance of water-soluble (W), acid-hydrolyzable (A), ethanol-soluble (E) and non-extractable (N) components in AM and EM fungi. Mycelia of S.verrucosum* and G.aggregatum* were assessed in a mixture with plant litter (details see Methods section).

We found that the biomass of AM fungi exhibits a distinct set of decomposability-related traits compared to that of EM fungi (outcomes of a perMANOVA test on the WAEN components: $\mathrm{p}=0.002, \mathrm{df}=1$; data for individual fungal species was treated as replicates within AM and EM fungal guilds). The unambiguous difference between centroids of AM and EM fungi in the multidimensional space of WAEN components (Fig.2) suggests that these two groups of fungi are likely to contribute to different pathways of soil C transformations as being direct sources of soil $\mathrm{C}$ compounds.

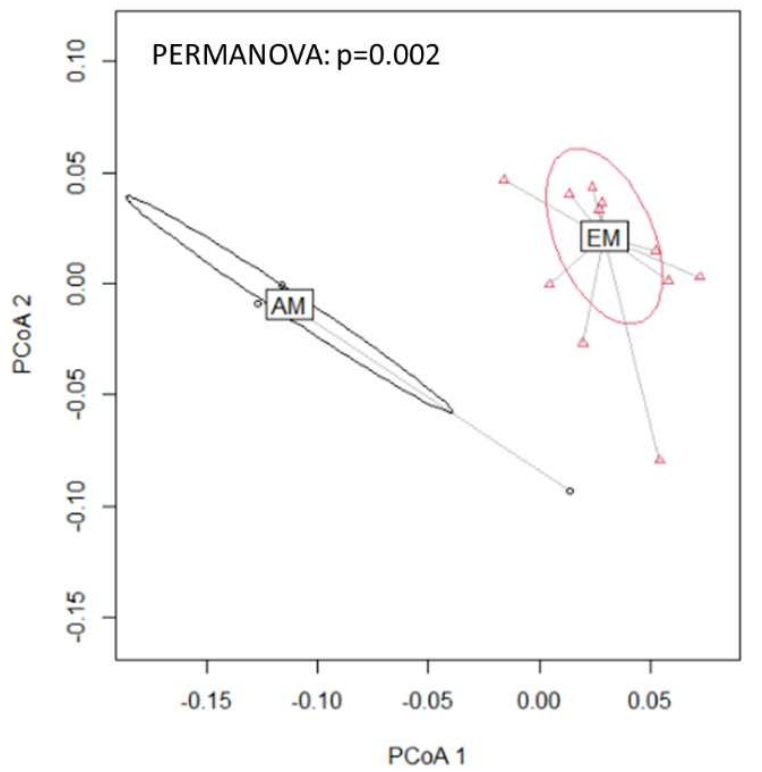


Subsequently, we examined which individual WAEN components differ among AM and EM fungi. We found that concentrations of the most easily decomposable component $(\mathrm{W})$, the ethanol-soluble fraction (E) and the most recalcitrant component $(\mathrm{N})$ were significantly higher in EM fungi (Mann-Whitney tests with data for individual fungi within a fungal guild treated as replicates; $\mathrm{p}<0.001, \mathrm{p}<0.001$ and $\mathrm{p}<0.05$, respectively; Fig.3a,c, and d). In contrast, AM fungi had a significantly higher A fraction (Mann-Whitney test conducted in the same manner as for W, A, and N components: $\mathrm{p}<0.001$; Fig.3b). While both A and E components are of intermediate recalcitrance, acid-hydrolysable components have been shown to have higher decomposability than ethanol-soluble components ${ }^{41}$. The higher relative amount of $\mathrm{E}$ and $\mathrm{N}$ components in $\mathrm{EM}$ fungi compared to that of $\mathrm{AM}$ fungi constitutes novel empirical evidence in support of previous suggestions ${ }^{23,42,43}$ that per fungal biomass units of EM fungi provide an important contribution to the soil pool of intact or partially oxidized mycorrhizal fungal biomass. At the same time, the high abundance of most easily decomposable $\mathrm{W}$ components supports empirical evidence of the high rate decomposability of EM fungal mycelium during the initial stages of decomposition $^{44,45}$.
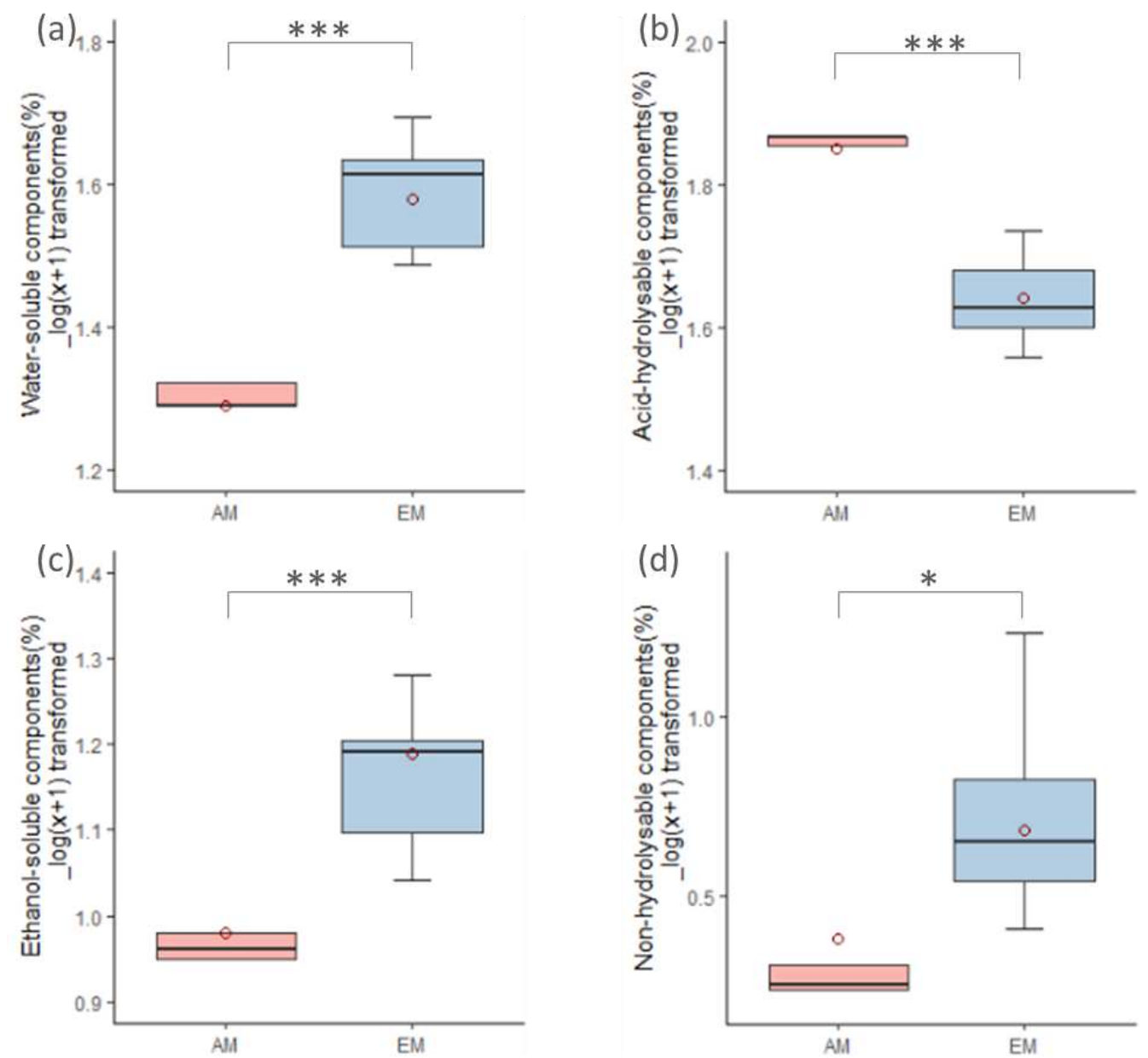
within boxes- weighted-median values within each mycorrhiza group, and red circles - weighted-mean of each mycorrhiza group.

We compared the magnitude of differences in recalcitrance of mycorrhizal fungal litter to the magnitude of differences in recalcitrance of plant leaf litter (see Methods section for details) which for decades has been recognized as the major factor controlling soil $\mathrm{C}$ dynamics ${ }^{10-12}$. Hereto we compared 4 plant functional types: evergreen trees, deciduous trees, evergreen shrubs, herbaceous plants. The differences between AM and EM mycorrhizal fungal species in chemical recalcitrance of litter, measured as the relative abundance of WAEN components, was nearly twice as large as the differences in chemical recalcitrance of litter between plant species of distinct functional types. For the particular case of the water-soluble components, it was even three times higher (Table.1). The effect sizes $\left(\eta^{2}\right)$ of the difference between mycorrhizal fungal guilds for each individual WAEN component were higher. This was particularly evident for the major components of $\mathrm{W}$ and A (see Fig.1) in the mycelium, which comprised the majority of the variation in chemical components. In contrast, a similar analysis conducted for plant species grouped into functional types (for details see Methods section) showed that the effect size of chemical differences of plant functional types was much smaller, and only acid-hydrolysable components contributed to the major variation in the group. Taken together, this suggests that the potential contribution to distinct pathways of $\mathrm{C}$ transformations differs markedly between mycorrhizal fungal guilds, and that differences in the decomposability pathways of mycorrhizal fungal material are even more striking than the differences observed in leaf litter among plant functional types, till now considered as one of the most important factors determining soil $\mathrm{C}$ circulation. Thus, chemical differences between mycorrhizal fungi types might be essential underestimated sources of (variation in) below-ground soil $\mathrm{C}$ dynamics.

Table.1 Effect sizes ( $n 2$, one-way ANOVA) of chemical composition differences in leaf litter within plant functional types and mycelial biomass within mycorrhizal fungal guilds

\begin{tabular}{lcccc}
\hline & $\begin{array}{c}\text { Water- } \\
\text { soluble }\end{array}$ & $\begin{array}{c}\text { Acid- } \\
\text { extractable }\end{array}$ & $\begin{array}{c}\text { Ethanol- } \\
\text { soluble }\end{array}$ & $\begin{array}{c}\text { Non- } \\
\text { extractable }\end{array}$ \\
\hline Mycorrhizal fungal guilds & 0.68 & 0.76 & 0.46 & 0.26 \\
Plant functional types & 0.20 & 0.41 & 0.28 & 0.19 \\
\hline
\end{tabular}

Our test of chemical recalcitrance of mycorrhizal mycelium biomass of multiple EM and AM fungal species provides the first empirical evidence of the inherent difference between $\mathrm{AM}$ and EM fungi in terms of their chemical composition related to the decomposition pathway. Differences between these fungal guilds in decomposability support and mechanistically underpin previous speculations that EM fungi might contain a higher ratio of components recalcitrant to decomposition than AM fungi ${ }^{5}$. While microbiologists seek to specify the fungus-specific macromolecular compounds and basic chemical elements, these characters are difficult to link to soil $\mathrm{C}$ cycle mechanisms. Instead of analysing individual chemical components or complex chemical compounds of fungal biomass that are possibly a proxy for decomposability ${ }^{5,9,31}$, we opted to characterize fungal biomass through general traits of litter quality known to drive soil C cycling ${ }^{41,46,47}$. Recently, it has 
been suggested that labile and recalcitrant $\mathrm{C}$ compounds originating from decomposing organic matter might follow distinct pathways of stabilization depending on the abundance of soil saprotrophic organisms ${ }^{48,49}$. This suggests that $\mathrm{C}$ components originating from mycorrhizal fungi of distinct guilds are likely involved in distinct pathways of $\mathrm{C}$ transformations in soil. Moreover, through the differential release of labile and more recalcitrant $\mathrm{C}$ components, the temporal dynamics of contributions of different mycorrhizal fungal guilds to distinct soil $\mathrm{C}$ transformation pathways will also differ among EM and AM fungi.

For decades, foliage litter and its variability among species or plant functional types has been considered as one of the main factor controlling soil $\mathrm{C}$ cycle process ${ }^{10}$. Our analysis shows that the magnitude of differences in chemical decomposability traits between fungi of distinct mycorrhizal guilds is much higher than that of the leaf litter of plant species belonging to distinct functional groups. This suggests that the quality of mycorrhizal fungal biomass is a critically important factor for pathways of soil $\mathrm{C}$ transformation processes. Such pathways have been previously hypothesized ${ }^{5,24}$ but in practice neglected or underestimated due to the high uncertainty associated with this phenomenon. Given that plants allocate a significant part (up to 30\%) of NPP to mycorrhizal fungal biomass ${ }^{20,22}$, an amount comparable to the allocation into plant leaves in some ecosystems ${ }^{50,51}$, the differential contributions of mycorrhizal fungal guilds to the processes of soil $\mathrm{C}$ turnover should be considered as a critical SOM formation factor. As mycorrhizal fungal necromass is among the most important sources of below ground soil $\mathrm{C}$ input, our results provide chemical quality information of soil $\mathrm{C}$ inputs which is essential in narrowing down major uncertainties in estimating soil $\mathrm{C}$ fluxes dynamics.

\section{Methods}

\section{Cultivation of $A M$ and EM fungi}

We selected available AM fungal species strains from the Glomeraceae family, as this family is globally the most dominant family of AM fungi ${ }^{52}$, while they can be grown in vitro producing reasonably large amounts of fungal biomass. We selected EM fungal species to cover relatively abundant strains of various families. In addition, we opted to use a higher number of EM fungi species compared to AM fungi, because (1) EM fungi consist of ca. 20,000-25,000 species ${ }^{53,54}$ which entail high diversity of chemical traits, while AM fungi have been known to exhibit lower diversity with ca. 300 species identified within this fungal phylum ${ }^{55-57}$, (2) mass-production of AM fungi to reach the amounts of biomass necessary for the recalcitrance assessments is complicated, necessitating hundreds of Petri plates. Through cultivation, all manipulations were conducted under sterile conditions to prevent contamination of fungal material, by using a laminar flow hood, and with sterile or sterilized laboratory material.

\section{EM fungi cultivation and sample preparation}

Original cultures of EM fungal species were obtained from Westerdijk Fungal Biodiversity Institute (the Netherlands), which also provided standard laboratory instructions for EMF 
cultivation (except strain of Scleroderma verrucosum, which was obtained from the collection of GINCO). Each species was inoculated in 30-80 Petri plates $(90 \mathrm{~mm}$, diameter), containing species-specific medium (Table.S1) solidified with bacteriological agar, then sealed with film and incubated in climate rooms (temperature $21-27^{\circ} \mathrm{C}$ according to the preference of each strain, in the dark) for 4-5 weeks (Fig.S1). Harvested fresh
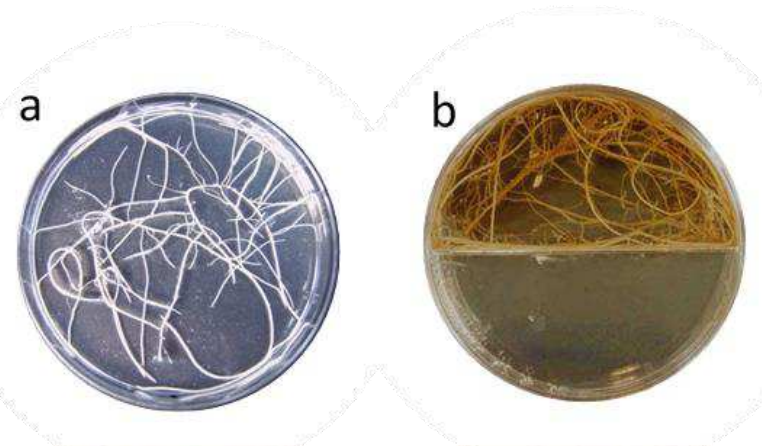

mycelium of EM fungi was washed with distilled water for 10 seconds, collected by filtration, and stored at $-20^{\circ} \mathrm{C}$. The frozen fungi biomass samples were dried using a freeze dryer or oven under $55^{\circ} \mathrm{C}$ for at least 12 hours (weighed after another $4 \mathrm{~h}$ until the weight is stable, drying methods see Table.S1), then stored at $-20^{\circ} \mathrm{C}$ before chemical recalcitrance assessments.
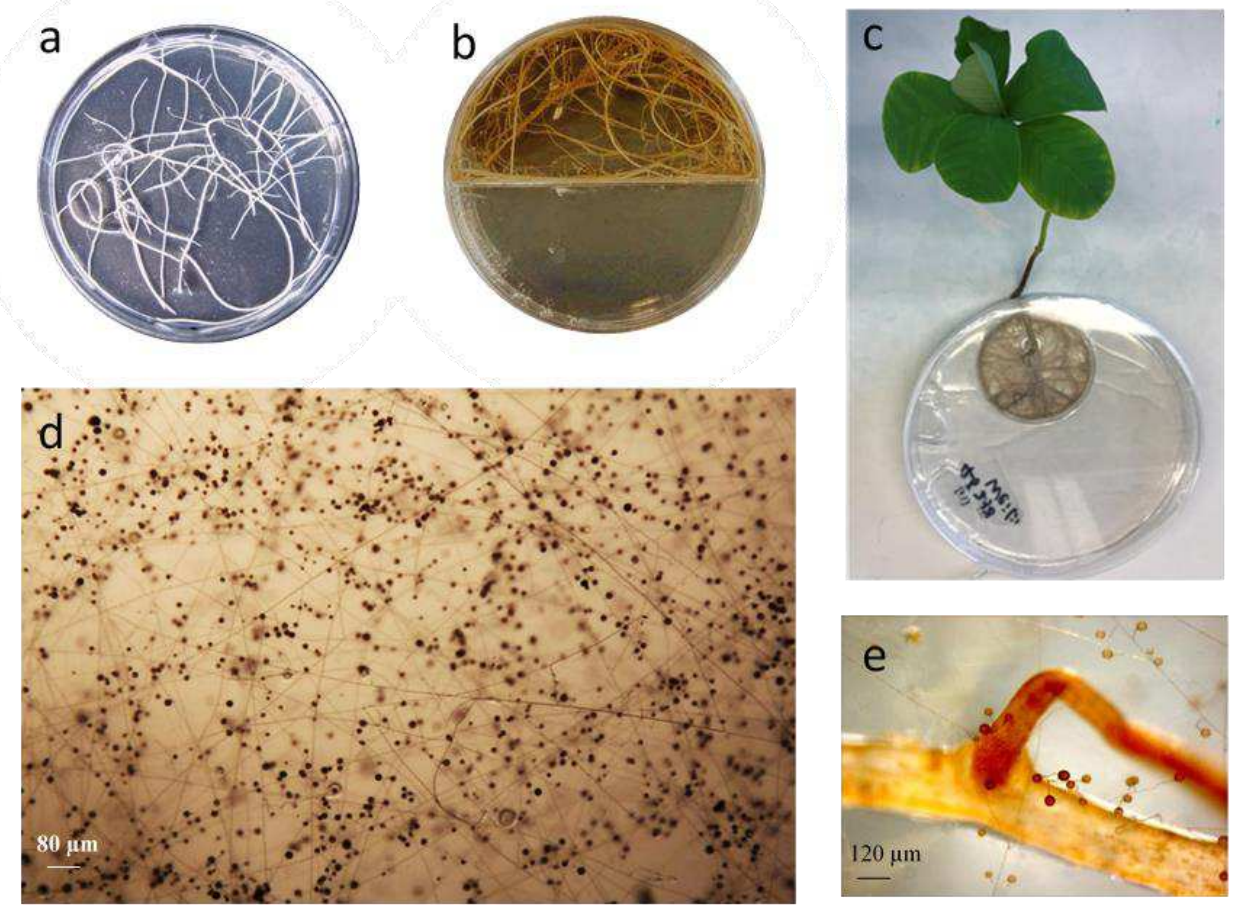

Fig.4 In vitro cultivation of mycorrhizal fungi arbuscular mycorrhizal fungi. Cultivation system in (a) monocompartmented or (b) bi-compartmented Petri dish on excised Ri T-DNA transformed root organs of carrot. (c) Cultivation with the whole plant of Crotalaria Spectabilis in a bi-compartment Petri dish system; (d) Mycelium and spore production of the AM fungus (Rhizophagus irregularis, MUCL 41833) grown in a bi-compartmented Petri dish and (e) a mono-compartment Petri dish.

\section{AM fungi cultivation and sample preparation}

All AM fungal strains were obtained from the Glomeromycota in vitro Collection (GINCO, Belgium). The cultivation protocol of AM fungi followed the methods well-established in the laboratory of mycology of UCLouvain (Belgium). As AM fungi are relatively slowgrowing, and there was no prior knowledge on biomass output among in vitro cultivation approaches, each strain was cultivated using four different systems (Fig.4): autotrophic whole plants system either with a Petri (S1) or a mesh (S2) root compartment (RC), transformed root organ culture (ROC) system in bi- (S3) or mono-compartmented (S4) Petri plates. In the end, we established over 600 AM systems, all biomass produced by each 
strain in the four different in vitro systems described below was needed to fulfil the standard amount required for the chemical analysis.

245 System S1 consisted of a lid of a small 50-mm-diameter Petri dish placed inside a large 246 145-mm-diameter Petri dish, to create an RC inside a mycelial compartment (MC) (Fig. 4c). System $S 2$ was similar to $S 1$ with the difference that a 55-mm-diameter cap made with 40- $\mu \mathrm{m}$ nylon mesh and filled with cotton was used as RC instead (Fig.S2). The RC contained roots of mycorrhizal plants to sustain fungal growth into the MC. Both compartments were filled with modified Strullu-Romand $\left(\mathrm{MSR}^{58}\right)$ medium without sucrose and vitamins. The large plates were covered with black plastic foil to minimize light exposure. In each large plate, the plant shoot grew outside through a 2-mm-diameter lateral opening sealed with sterile silicon grease as described ${ }^{59}$. The systems were kept in a growth chamber with a 16-hour photoperiod, $130 \mu \mathrm{mol} \mathrm{m} \mathrm{m}^{-2} \mathrm{~s}^{-1}$ light intensity, $27{ }^{\circ} \mathrm{C}$ temperature, and $80 \%$ relative humidity. Each RC was refilled with medium every 2-3 weeks.

The system S3 (Fig.4b) consisted of 94-mm-diameter bi-compartmented Petri plates with $\mathrm{RC}$ and MC. The RC contained mycorrhizal Ri T-DNA transformed roots clone DC2 of Daucus carota growing in MSR medium to sustain the fungal growth into the MC. The MC was filled with MSR medium without sucrose and vitamins. These bi-compartmented plates were incubated inverted in the dark at $27^{\circ} \mathrm{C}$ for 6 months; The system S4 (Fig.4a) consisted of a 145-mm-diameter mono-compartmented Petri plate with mycorrhizal Ri TDNA transformed roots of D.carota clone DC2 growing in MSR medium ${ }^{58}$. The plates were incubated inverted in the dark at $27^{\circ} \mathrm{C}$ for $4-5$ months.

For systems S1, S2, and S3, roots were trimmed before invading the MC to keep the MC root-free. Once the MC was full with mycelium, the medium was harvested to extract the mycelium as described below, and the MC was re-filled with medium to allow fungal regrowth. The harvesting procedure was repeated for each plate every 4 to 6 weeks until another 6-10 months according to the productivity of each plate; For system S4, only the sections of the medium without any roots were harvested once to exclude roots and root exudates after incubation.

272 The absence of roots in the harvested medium was carefully evaluated and confirmed using 273 a stereomicroscope. For all different systems and strains, the harvested medium which only contained mycelium was immediately liquefied inside a beaker in a water bath at $70{ }^{\circ} \mathrm{C}$ for 2 hours - this procedure also killed the mycelium. The mycelium was then collected using a $38-\mu \mathrm{m}$ filter, washed with demineralised water for 10 seconds to remove any remnants of medium and root exudates (only possibly exist in the harvested medium from S4), and stored at $-20^{\circ} \mathrm{C}$ until further use. Prior to chemical analyses, all mycelia was dried using the same procedure as for the EM fungi described above (Table.S1).

Chemical recalcitrance analysis

281 Mycelia were examined for the chemical composition of different recalcitrance in the

282 laboratory of Natural Resources Institute (Finland). Litter quality of fungal dead material 
was determined by examining the samples for different chemical decomposable substances: water-soluble (W), ethanol- or dichloromethane-soluble (E), acid-hydrolysable (A) and non-extractable $(\mathrm{N})$ components. These components are key to determining the dynamics of litter decomposition and soil $\mathrm{C}$ cycling in soil $\mathrm{C}$ modelling ${ }^{41,46,60}$. The decomposability of each component was determined based on the Yasso soil $\mathrm{C}$ model ${ }^{41,46}$ and followed the order W-A-E-N. The amounts of extractable substances were determined gravimetrically by incubating samples with a solvent and weighing the samples after filtration and drying. Mass loss during each extraction was considered to be equal to the amount of a compound being extracted. For details of the protocols, see Ryan et al. (1990) and Wieder and Starr (1998). The raw measurement results corresponding to Fig.1 are provided in Table.S2. Samples that did not reach $0.5 \mathrm{~g}$ were measured with a mixture of plant litter (with a known content of WAEN components) to reach the necessary quantity for analysis, and the chemical composition was calculated based on the proportion of fungal biomass in the sample (details see Note.S1).

\section{Data process and statistics}

We assessed the significance of the overall differences in recalcitrance between AM and EM fungi, with the permutational analysis of variance - perMANOVA ${ }^{63}$, performed with 999 permutations in the Vegan package in R. WAEN values were log-transformed to meet model assumptions. Dispersions of beta diversity (the distance from an individual measure to the group's centroid) were calculated by each beta diversity metric within AM and EM fungal groups for estimating within-group variation across individuals. Significant differences in beta diversity variation ${ }^{64}$ were tested using permutational statistical tests for the homogeneity of group dispersions with 999 permutations in Vegan. We used Principal Coordinates Analysis (PCoA) for visualization of the data present in the beta diversity distance matrix (Fig.3).

We tested the hypothesis that AM fungi exhibit higher amounts of easily soluble, and acidhydrolysable compounds, while EM fungi have higher amounts of compounds that are neither soluble nor hydrolysable, by a non-parametric Mann-Whitney U test to determine if there were statistically significant differences in each chemical component between the two mycorrhizal groups. To account for the fact that WAEN of two fungal strains were assessed in a mixture with plant litter, all statistical analyses of fungal WAEN were conducted as weighted analyses according to the accuracy assessment for the results of sample from a mixture (details see Notes.S1).

We examined the magnitude of the difference between the recalcitrance of mycorrhizal fungal types vs. the recalcitrance of plant material (Hypothesis 2) comparing the effect size- Eta square $\left(\eta^{2}\right)^{65}$ of ANOVAs on WAEN values of AM vs EM fungi to the effect sizes of ANOVAs on WAEN of plant functional types (other effect size indices are provided in supplements, Notes.S2). To meet the normality assumptions, WAEN values were log-transformed.

The data on plant functional types used for this analysis were obtained as follows: We gathered plant leaf WAEN chemical composition data for 59 species from CIDET $^{32}$ and 
LIDET $^{33}$ datasets (details see Notes.S2). Those data were grouped into the evergreen tree, deciduous tree, evergreen shrub and herb, based on plant growth form information from the TRY database ${ }^{66}$. Species with multiple form definitions were defined according to the highest occurrence frequency ${ }^{67}$.

\section{Data availability}

All data generated or analysed during this study are included in this article (and its supplementary information files).

\section{Acknowledgement}

This research was supported by the vidi grant 016.161 .318 (issued to N.S. by The Netherlands Organization for Scientific research) and China Scholarship Council (CSC, grant No. 201706040071 issued to W.H.). We appreciate the Natural Resources Institute Finland and Prof. Hannu Fritze for supporting chemical analysis, colleagues of the Soilprocess group and Chen Li (CML, Leiden University) for discussion. We gratefully acknowledge the researchers whose data are used in the analyses.

\section{Author contribution statements}

W.H., P.B. and N.S. conceived the original idea and plan the project. S.D. and J.L. were involved in planning the project. W.H. carried out the cultivation with assistance from S.D. and M.C. on AM fungi. J.H. provided the sample measurements and processed the experimental data. W.H. performed the numerical calculations and analysed the data. P.B, N.S, J.H. and T.V. aided in interpreting the results. W.H. and N.S. wrote the manuscript in consultation with P.B, S.D., M.C., J.H., T.V. and J.L.. All authors discussed the results and commented on the manuscript.

\section{Competing interests}

The authors declare no competing interests.

\section{Supplementary Information}

Table.S1 Samples of AM and EM fungi with corresponding cultivation and drying details Table.S2 Chemical compositions of AM and EM fungi samples

Fig.S1 Cultivations for EM fungi

Fig.S2 Schematic representation of two physically different autotrophic whole plant systems (S1\&S2)

Notes.S1 Accuracy assessment for results of litters measured with the mixture Notes.S2 Plant litter data and statistics

\section{References}

1. Melillo, J. M. et al. Soil warming and carbon-cycle feedbacks to the climate system. Science (80-. ). 298, 2173-2176 (2002).

2. Stockmann, U. et al. The knowns, known unknowns and unknowns of sequestration of soil organic carbon. Agric. Ecosyst. Environ. 164, 80-99 (2013). 
3. Sokol, N. W., Sanderman, J. \& Bradford, M. A. Pathways of mineral-associated soil organic matter formation: Integrating the role of plant carbon source, chemistry, and point of entry. Glob. Chang. Biol. 25, 12-24 (2019).

4. Krull, E. S., Baldock, J. A. \& Skjemstad, J. O. Importance of mechanisms and processes of the stabilisation of soil organic matter for modelling carbon turnover. Funct. Plant Biol. 30, 207-222 (2003).

5. Langley, J. A. \& Hungate, B. A. Mycorrhizal controls on belowground litter quality. Ecology 84, 2302-2312 (2003).

6. Strickland, M. S., Osburn, E., Lauber, C., Fierer, N. \& Bradford, M. A. Litter quality is in the eye of the beholder: Initial decomposition rates as a function of inoculum characteristics. Funct. Ecol. 23, 627-636 (2009).

7. Coûteaux, M. M., Bottner, P. \& Berg, B. Litter decomposition, climate and litter quality. Trends Ecol. Evol. 10, 63-66 (1995).

8. Prescott, C. E. Litter decomposition: What controls it and how can we alter it to sequester more carbon in forest soils? Biogeochemistry 101, 133-149 (2010).

9. Fernandez, C. W., Heckman, K., Kolka, R. \& Kennedy, P. G. Melanin mitigates the accelerated decay of mycorrhizal necromass with peatland warming. Ecol. Lett. 22, 498505 (2019).

10. Brovkin, V. et al. Plant-driven variation in decomposition rates improves projections of global litter stock distribution. Biogeosciences 9, 565-576 (2012).

11. Aponte, C., García, L. V. \& Marañón, T. Tree species effect on litter decomposition and nutrient release in mediterranean oak forests changes over time. Ecosystems 15, 12041218 (2012).

12. Hättenschwiler, S. \& Jørgensen, H. B. Carbon quality rather than stoichiometry controls litter decomposition in a tropical rain forest. J. Ecol. 98, 754-763 (2010).

13. Heijden, M. G. a Van Der et al. Mycorrhizal ecology and evolution: the past, the present, and the future. New Phytol. 205, 1406-1423 (2015).

14. Lin, G., McCormack, M. L., Ma, C. \& Guo, D. Similar below-ground carbon cycling dynamics but contrasting modes of nitrogen cycling between arbuscular mycorrhizal and ectomycorrhizal forests. New Phytol. 213, 1440-1451 (2017).

15. Högberg, M. N. \& Högberg, P. Extramatrical ectomycorrhizal mycelium contributes onethird of microbial biomass and produces, together with associated roots, half the dissolved organic carbon in a forest soil. New Phytol. 154, 791-795 (2002).

16. Leake, J. et al. Networks of power and influence: the role of mycorrhizal mycelium in controlling plant communities and agroecosystem functioning. Can. J. Bot. 82, 10161045 (2004).

17. Bååth, E., Nilsson, L. O., Göransson, H. \& Wallander, H. Can the extent of degradation of soil fungal mycelium during soil incubation be used to estimate ectomycorrhizal biomass in soil? Soil Biol. Biochem. 36, 2105-2109 (2004). 
18. Kaiser, C. et al. Exploring the transfer of recent plant photosynthates to soil microbes: Mycorrhizal pathway vs direct root exudation. New Phytol. 205, 1537-1551 (2015).

19. Konvalinková, T., Püschel, D., Řezáčová, V., Gryndlerová, H. \& Jansa, J. Carbon flow from plant to arbuscular mycorrhizal fungi is reduced under phosphorus fertilization. Plant Soil 419, 319-333 (2017).

20. Ouimette, A. P. et al. Accounting for carbon flux to mycorrhizal fungi may resolve discrepancies in forest carbon budgets. Ecosystems 23, 715-729 (2019).

21. Wallander, H., Nilsson, L. O., Hagerberg, D. \& Bååth, E. Estimation of the biomass and seasonal growth of external mycelium of ectomycorrhizal fungi in the field. New Phytol. 151, 753-760 (2001).

22. Allen, M. F. \& Kitajima, K. Net primary production of ectomycorrhizas in a California forest. Fungal Ecol. 10, 81-90 (2014).

23. Godbold, D. L. et al. Mycorrhizal hyphal turnover as a dominant process for carbon input into soil organic matter. Plant Soil 281, 15-24 (2006).

24. Frey, S. D. Mycorrhizal fungi as mediators of soil organic matter dynamics. Annu. Rev. Ecol. Evol. Syst. 50, 237-259 (2019).

25. Brundrett, M. C. \& Tedersoo, L. Evolutionary history of mycorrhizal symbioses and global host plant diversity. New Phytol. 220, 1108-1115 (2018).

26. Soudzilovskaia, N. A. et al. Global mycorrhizal plant distribution linked to terrestrial carbon stocks. Nat. Commun. 10, 1-10 (2019).

27. Phillips, R. P., Brzostek, E. \& Midgley, M. G. The mycorrhizal-associated nutrient economy : a new framework for predicting carbon - nutrient couplings in temperate forests. New Phytol. 41-51 (2013).

28. Miyauchi, S. et al. Large-scale genome sequencing of mycorrhizal fungi provides insights into the early evolution of symbiotic traits. Nat. Commun. 11, 5125 (2020).

29. Harley, J. L. Fungi in Ecosystems. J. Ecol. 59, 653 (1971).

30. Fernandez, C. W., Langley, J. A., Chapman, S., McCormack, M. L. \& Koide, R. T. The decomposition of ectomycorrhizal fungal necromass. Soil Biology and Biochemistry 93, 38-49 (2016).

31. Fernandez, C. W. \& Koide, R. T. Initial melanin and nitrogen concentrations control the decomposition of ectomycorrhizal fungal litter. Soil Biol. Biochem. 77, 150-157 (2014).

32. Trofymow, J. A. The Canadian Institute Decomposition Experiment (CIDET) : project and site establishment report / J.A. Trofymow and the CIDET Working Group. (1998).

33. Gholz, H. L., Wedin, D. A., Smitherman, S. M., Harmon, M. E. \& Parton, W. J. Long-term dynamics of pine and hardwood litter in contrasting environments: Toward a global model of decomposition. Glob. Chang. Biol. 6, 751-765 (2000).

34. Kögel-Knabner, I. The macromolecular organic composition of plant and microbial residues as inputs to soil organic matter. Soil Biol. Biochem. 34, 139-162 (2002). 
35. Zeglin, L. H. \& Myrold, D. D. Fate of Decomposed Fungal Cell Wall Material in Organic Horizons of Old-Growth Douglas-fir Forest Soils. Soil Sci. Soc. Am. J. 77, 489-500 (2013).

36. Kleber, M. et al. Mineral-organic associations: formation, properties, and relevance in soil environments. in Advances in Agronomy 130, 1-140 (2015).

37. Fortin, J. A. et al. Arbuscular mycorrhiza on root-organ cultures. Can. J. Bot. 80, 1-20 (2002).

38. Declerck, S., Séguin, S. \& Dalpé, Y. The monoxenic culture of Arbuscular Mycorrhizal fungi as a tool for germplasm collections. in In Vitro Culture of Mycorrhizas 17-30 (SpringerVerlag, 2005).

39. Lalaymia, I. \& Declerck, S. The Mycorrhizal Donor Plant (MDP) in vitro culture system for the efficient colonization of whole plants. 2146, (Springer US, 2020).

40. Crous, P. W., Verkley, G. J. M., Groenewald, J. Z. \& Houbraken, J. Westerdijk Laboratory Manual Series 1: Fungal Biodiversity. (2019).

41. Tuomi, M. et al. Leaf litter decomposition-Estimates of global variability based on Yasso07 model. Ecol. Modell. 220, 3362-3371 (2009).

42. Clemmensen, K. E. et al. Carbon sequestration is related to mycorrhizal fungal community shifts during long-term succession in boreal forests. New Phytol. 205, 15251536 (2015).

43. Averill, C., Turner, B. L. \& Finzi, A. C. Mycorrhiza-mediated competition between plants and decomposers drives soil carbon storage. Nature 505, 543-5 (2014).

44. Staddon, P. L., Ramsey, C. B., Ostle, N., Ineson, P. \& Fitter, A. H. Rapid turnover of hyphae of mycorrhizal fungi determined by AMS microanalysis of $14 C$. Science (80-. ). 300, 11381140 (2003).

45. Adamczyk, B., Sietiö, O., Biasi, C. \& Heinonsalo, J. Interaction between tannins and fungal necromass stabilizes fungal residues in boreal forest soils. New Phytol. 223, 16-21 (2019).

46. Liski, J., Palosuo, T., Peltoniemi, M. \& Sievänen, R. Carbon and decomposition model Yasso for forest soils. Ecol. Modell. 189, 168-182 (2005).

47. Guendehou, G. H. S. et al. Decomposition and changes in chemical composition of leaf litter of five dominant tree species in a West African tropical forest. Trop. Ecol. 55, 207220 (2014).

48. Paterson, E. et al. Labile and recalcitrant plant fractions are utilised by distinct microbial communities in soil: Independent of the presence of roots and mycorrhizal fungi. Soil Biol. Biochem. 40, 1103-1113 (2008).

49. Cotrufo, M. F., Wallenstein, M. D., Boot, C. M., Denef, K. \& Paul, E. The Microbial Efficiency-Matrix Stabilization (MEMS) framework integrates plant inputs form stable soil organic matter? Glob. Chang. Biol. 19, 988-995 (2013).

50. Xia, J. et al. Global patterns in Net Primary Production allocation regulated by environmental conditions and forest stand age: a model-data comparison. J. Geophys. Res. Biogeosciences 124, 2039-2059 (2019). 
51. Malhi, Y., Doughty, C. \& Galbraith, D. The allocation of ecosystem net primary productivity in tropical forests. Philos. Trans. R. Soc. B Biol. Sci. 366, 3225-3245 (2011).

52. Davison, J. et al. Plant functional groups associate with distinct arbuscular mycorrhizal fungal communities. New Phytol. 226, 1117-1128 (2020).

53. Tedersoo, L., May, T. W. \& Smith, M. E. Ectomycorrhizal lifestyle in fungi: global diversity, distribution, and evolution of phylogenetic lineages. Mycorrhiza 20, 217-263 (2010).

54. Rinaldi, A. C. ., Comandini, O. . \& Kuyper, T. W. Ectomycorrhizal fungal diversity: separating the wheat from the chaff. Fungal Divers. 33, 1-45 (2008).

55. Krüger, M., Krüger, C., Walker, C., Stockinger, H. \& Schüßler, A. Phylogenetic reference data for systematics and phylotaxonomy of arbuscular mycorrhizal fungi from phylum to species level. New Phytol. 193, 970-984 (2012).

56. Lee, E.-H., Eo, J.-K., Ka, K.-H. \& Eom, A.-H. Diversity of arbuscular mycorrhizal fungi and their roles in ecosystems. Mycobiology 41, 121-125 (2013).

57. Schüßler, A., Schwarzott, D. \& Walker, C. A new fungal phylum, the Glomeromycota: phylogeny and evolution. Mycol. Res. 105, 1413-1421 (2001).

58. Declerck, S., Strullu, D. G. \& Plenchette, C. Monoxenic culture of the intraradical forms of Glomus sp. isolated from a tropical ecosystem: a proposed methodology for germplasm collection. Mycologia 90, 579 (1998).

59. Voets, L. et al. Extraradical mycelium network of arbuscular mycorrhizal fungi allows fast colonization of seedlings under in vitro conditions. Mycorrhiza 19, 347-356 (2009).

60. Viskari, T. et al. Soil carbon estimates by Yasso15 model improved with state data assimilation. 1-22 (2020). doi:10.5194/gmd-2020-141

61. Ryan, M. G., Melillo, J. M. \& Ricca, A. A comparison of methods for determining proximate carbon fractions of forest litter. Can. J. For. Res. 20, 166-171 (1990).

62. Wieder, R. K. \& Starr, S. T. Quantitative determination of organic fractions in highly organic, Sphagnum peat soils. Commun. Soil Sci. Plant Anal. 29, 847-857 (1998).

63. Anderson, M. J. Permutational Multivariate Analysis of Variance (PERMANOVA). Wiley StatsRef Stat. Ref. Online 1-15 (2017).

64. Anderson, M. J., Ellingsen, K. E. \& McArdle, B. H. Multivariate dispersion as a measure of beta diversity. Ecol. Lett. 9, 683-693 (2006).

65. Tomczak, M. \& Tomczak, E. The need to report effect size estimates revisited. An overview of some recommended measures of effect size. Trends Sport Sci. 1, 19-25 (2014).

66. Kattge, J. et al. TRY - a global database of plant traits. Glob. Chang. Biol. 17, 2905-2935 (2011).

67. Engemann, K. et al. A plant growth form dataset for the New World. Ecology 97, 3243 (2016). 


\section{Supplementary Files}

This is a list of supplementary files associated with this preprint. Click to download.

- Mst2WeilinSupplementaryCB.pdf 